\title{
In vitro responses and production of phytochemicals of potential medicinal value in nutmeg, Myristica fragrans Houtt.
}

\author{
R. Indira lyer*, G. Jayaraman and A. Ramesh \\ Department of Genetics, Dr. A.L.Mudaliar Post Graduate Institute of Basic Medical Sciences, University of Madras \\ (Taramani Campus), Chennai-600113, India \\ riiyer@yahoo.co.in
}

Abstract: The in vitro production of phytochemicals by the embryogenic cultures of nutmeg- Myristica fragrans Houtt., a tropical tree of considerable commercial and medicinal value, was investigated. The regeneration potential of the somatic embryos and the morphogenetic responses of foliar explants were also studied. The metabolite profiling of the long term embryogenic cultures established from zygotic embryos in media with activated charcoal, revealed the presence of several monoterpenes and essential oils including $\alpha \& \beta$-pinene, myristicin, safrole, methyl eugenol and betasitosterol. The essential oil profile varied with the age of the cultures and the 3 week old cultures had a rich variety of monoterpenes. The spent charcoal medium of these embryogenic cultures exhibited strong anti-microbial activity against the pathogens Salmonella typhi and Staphylococcus aureus. This is considered to be the first report of in vitro production of phytochemicals by the embryogenic mass. The results obtained in this study suggest that both the embryogenic cultures and the spent charcoal medium can act as sources of products of pharmacological interest and provide a basis for further biotechnological investigations of this rare, medicinally important species and for conservation of its germplasm by cryopreservation. Germination of somatic embryos derived from zygotic embryos was achieved in media with NAA. Direct formation of somatic embryos was achieved in leaf explants from juvenile plants in MS media with kinetin, 2,4-D and NAA.

Keywords: Embryogenic, myristicin, safrole, antimicrobial, tissue culture, medicinal plant.

Abbreviations: AVG: L- $\alpha-(2-a m i n o e t h o x y v i n y l)-$ glycine$\mathrm{HCl}$; BA: 6-benzylaminopurine; 2,4-D: 2,4dichlorophenoxyacetic acid; $\mathrm{GA}_{3}$ : gibberellic acid; GCMS: gas chromatography-mass spectrometry; HPLC: high performance liquid chromatography; IAA: indole-3acetic acid; MS: Murashige and Skoog; NAA: naphthaleneacetic acid; PGR: plant growth regulators; TDZ: thidiazuron.

Introduction

Nutmeg (Myristica fragrans Houtt.), a tropical evergreen dioecious tree with a narrow range of distribution is the source of the high value medicinal spices, nutmeg (endosperm) and mace (the reddish aril) with immense phytochemical diversity (Latha et al., 2005) and is a horticultural crop of great importance. Recent reports on its anti-bacterial, anti-viral, anti-diabetic, antileukaemic effects and other biological activities (Latha et al., 2005; Yang et al., 2006; Chirathaworn et al., 2007) indicate its enormous therapeutic potential. Conventional propagation of Myristica fragrans is hampered by its recalcitrant seeds, slow growth, a long juvenile phase and scarcity of propagules. It is essential to apply in vitro approaches to augment the availability of plant material for production of its valuable secondary metabolites and to aid its conservation. However culture of woody species is difficult and work with tropical woody angiosperms including fruit and nut species (Gomez-Lim \& Litz, 2004; Merkle \& Nairn, 2005) has lagged far behind herbaceous species mainly because of limited availability of explants, polyphenolic exudation and poor germination (Jain, 2006). Nutmeg is highly recalcitrant to tissue culture specially owing to the heavy leaching of phenolics and literature on its in vitro propagation is scanty. Direct somatic embryogenesis was achieved from intact and fragmented zygotic embryos (lyer et al., 2000). Owing to the heavy leaching of toxic metabolites from the zygotic embryo explants into the medium the cultured tissues failed to survive in the absence of activated charcoal. However it was observed that the browning and necrosis of explants could be controlled by incorporation of activated charcoal $0.3-0.5 \%(\mathrm{w} / \mathrm{v})$ in the media presumably due to adsorption and sequestration of the inhibitory metabolites leached out of the tissues and resulted in direct high frequency somatic embryogenesis (lyer et al., 2000; lyer, 2007) from intact or fragmented zygotic embryos. The objective of the present work is to study the potential of the embryogenic cultures of nutmeg for continuous in vitro production of its valuable bioactive phytochemicals and to examine the antimicrobial activity of the inhibitory substances in the leachates in the spent medium of the embryogenic cultures for possible application in human healthcare strategies. The regeneration potential of the somatic embryos and the morphogenetic potential of foliar explants from juvenile material were also explored.

\section{Materials and methods}

\section{Plant Material}

The plant material was obtained from State Horticultural Farm, Kallar, Tamil Nadu. Zygotic embryos from freshly harvested ripe fruits from elite trees and immature leaves (about $4-5 \mathrm{~cm}$ long) from juvenile shoots sprouted by detopping 3 month old saplings were used as explants.

Establishment of embryogenic cultures of $M$. fragrans from zygotic embryos

The detailed protocol for induction of direct somatic embryogenesis from intact and fragmented zygotic embryos and establishment of embryogenic cultures in $M$. fragrans has already been described (lyer et al., 2000). Embryogenic cultures were established in MS (Murashige \& Skoog,1962) medium at pH 5.7 with
Research article (Rapid publication)

Clndian Society for Education and Environment (iSee)
"Embryogenic culture of nutmeg" http://www.indjst.org
Indira lyer et al. Indian J.Sci.Technol. 
activated charcoal ( $300 \mathrm{mg} \mathrm{L}^{-1}$ ), $3 \%$ sucrose, $0.8 \%$ agar and various combinations of growth regulators and maintained by subculture at regular intervals in media with activated charcoal and with the same or different hormonal combinations. The data were subjected to one way analysis of variance (ANOVA) and the difference between the means was compared by Fisher's least significant difference test (LSD). Percentage data were arcsine square root transformed prior to analysis.

Establishment of embryogenic cultures of $M$. fragrans from immature leaves

Immature leaves (about 4-5 cm long) from juvenile shoots sprouted by detopping 3 month old saplings were used as explants. The leaves were washed in running tap water for $10 \mathrm{~min}$ and surface- sterilized in a laminar flow cabinet. The leaves were dipped in $75 \%$ ethanol for 30 sec, immersed in $1 \%$ sodium hypochlorite solution for 3 min and after several rinses with sterilized distilled water were blotted, cut into pieces and cultured in MS (Murashige \& Skoog, 1962) medium with 3\% sucrose and various combinations of growth regulators. The $\mathrm{pH}$ of all media was adjusted to 5.7 before addition of agar $(0.8 \%)$ and autoclaved at $121^{\circ} \mathrm{C}$ and $1.1 \mathrm{~kg} \mathrm{~cm}^{-2}$ for 20 min. Cultures were grown at $24 \pm 1^{\circ} \mathrm{C}$ in continuous light provided by cool white fluorescent lamps (Philips, India) with a photon flux density of $35 \mu \mathrm{mol} \mathrm{m} \mathrm{m}^{-2}$.

Phytochemical studies of the embryogenic mass from the cultured zygotic embryos and the spent medium

Analysis of the embryogenic mass by headspace GCMS

The embryogenic mass from the cultured zygotic embryos were harvested at 1,3 and 5 weeks after culture initiation and after recording the fresh weights, was directly analysed by headspace GCMS using an Agilent 5973-6890 GCMS system with a DB-5 capillary column $(30 \mathrm{~m} \times 0.25 \mathrm{~mm}$; film thickness $0.25 \mu \mathrm{m})$. The operating conditions were as follows - Helium carrier gas flow: $1 \mathrm{~mL} / \mathrm{min}$; Temperature programming: $50^{\circ} \mathrm{C}(1 \mathrm{~min})$, ramp of $10^{\circ} \mathrm{C}$ per min to $250^{\circ} \mathrm{C}$, hold for $10 \mathrm{~min}$, ramp of $10^{\circ} \mathrm{C}$ per min to $280^{\circ} \mathrm{C}$, hold for $2 \mathrm{~min}$; Injector temperature: $250^{\circ} \mathrm{C}$; El: $70 \mathrm{eV}$. The Chemstation software with the Wiley GCMS library was used to analyse the eluted volatiles and identify the compounds.

Analysis of the solvent extracts of the embryogenic mass from zygotic embryos

a) Ethanolic extract. The embryogenic mass from 4-5 week old cultures was crushed in a mortar and pestle in $80 \%$ ethanol, centrifuged and the supernatant concentrated by evaporation in vacuo. HPLC analysis of the extract was performed using a gradient solvent system essentially as described by Ehlers et al., (1998) using a Phenomenex ODS column. The injection volume was $5 \mu \mathrm{L}$. The standards myristicin (Sigma), safrole (Sigma), eugenol and methyl eugenol were used. The ethanolic extract was also analysed by GC-MS using a DB-5 capillary column.

b) Dichloromethane extract. The embryogenic mass was powdered in liquid nitrogen in a mortar and pestle
Vol.2 No 4 (Mar. 2009)

ISSN: 0974- 6846

followed by extraction with $80 \%$ methanol for one hour with periodic shaking and then with dichloromethane and an equal amount of water. After centrifugation for $6 \mathrm{~min}$ at $1000 \mathrm{~g}$, the aqueous layer was discarded and the organic layer was analysed by GC- MS using an Elite$5 \mathrm{MS}$ column as described by Koulman et al (2001).

Analysis of the ethanolic extract of the spent medium of the embryogenic cultures from zygotic embryos

The spent medium of the embryogenic cultures from zygotic embryos was extracted with $80 \%$ ethanol, centrifuged and the supernatant concentrated by evaporation in vacuo and analysed by GC-MS using a DB-5 capillary column.

Elicitor treatment of zygotic embryos and metabolite profiling by headspace GCMS

The elicitors used were salicylic acid $(100 \mu \mathrm{M})$ or chitosan $\left(100 \mathrm{mg} \mathrm{L}^{-1}\right)$ and were added to the medium before sterilization. Chitosan solution was prepared in acetic acid as described by Komaraiah et al (2003). Headspace GC-MS analysis of the embryogenic mass was carried out 4 weeks after culture of the zygotic embryos.

Assay of anti bacterial activity of extract of the spent charcoal medium

The anti- bacterial activity of the ethanolic extract of the spent medium of the embryogenic cultures from the zygotic embryos against selected gram-positive and gram-negative organisms was assayed by the disc diffusion (Jorgensen et al., 1999) method using 5-10 $\mu \mathrm{L}$ of extract. All tests were performed in duplicate. Commercial anti-bacterial test discs containing ciprofloxacin $(5 \mu \mathrm{g} /$ disc) were used as positive controls.

Results and discussion

Establishment of long term embryogenic cultures from zygotic embryos

In this work, we found that embryogenic response was obtained with zygotic embryos in all media with activated charcoal (Fig. 1a) regardless of the combinations of growth regulators (Table 1 ) used and that all PGRs employed could elicit embryogenic response. The somatic embryos turned green in about 2 weeks and massive proliferation was seen (Fig. 1b). Biomass weighing about $1.5 \mathrm{~g}$ could be obtained from each explant in 4 weeks. The embryogenic culture system could be maintained over a period of $10-12$ months by repeated subculture at 4 to 6 weeks intervals in MS media with activated charcoal and with the same or different hormonal combinations resulting in further proliferation of the embryogenic mass. An in vitro protocol for the continuous production of the valuable biomass by repetitive somatic embryogenesis was obtained. Among the generated somatic embryos, morphological abnormalities were often found resulting from fused cotyledons, fused embryos, multicotyledonary forms etc. Similar abnormal forms have been reported in many woody plants (Canhoto et al., 2006). However development of normal bicotyledonary forms in nutmeg
Research article (Rapid publication)

CIndian Society for Education and Environment (iSee)
"Embryogenic culture of nutmeg" http://www.indjst.org
Indira lyer et al. Indian J.Sci.Technol. 
was obtained by treatment with AVG $\left(0.1 \mathrm{mg} \mathrm{L}^{-1}\right)$ or jasmonic acid $(10 \mu \mathrm{M})$ as reported in mango and saffron (Chaturvedi et al., 2003; Blazquez et al., 2004).

In vitro germination of somatic embryos

Somatic embryos germinated by root formation (Table 2; Fig 2a) after subculture of the clumps of somatic

embryos in media with NAA. Shoot development was promoted by TDZ and $\mathrm{GA}_{3}$ (Fig.2b). In vitro germination was obtained only in $15 \%$ of the embryogenic cultures established initially from zygotic embryos. This is consistent with other earlier reports of the poor rates of somatic embryo germination associated with the presence of abnormal forms (Distabanjong \& Geneve,1997; Canhoto et al., 2006) being a major impediment to the commercial application of this technique (Trigiano et al., 1999) in woody species.

Fig.3. Direct somatic embryogenesis in leaf segments of Myristica fragrans. (a) Clumps of well formed globular somatic embryos in 9 week old cultures; (b) 12 week old cultures showing pale yellow transluscent globular forms; (c) somatic embryos after transfer to fresh medium . (bar=1mm).
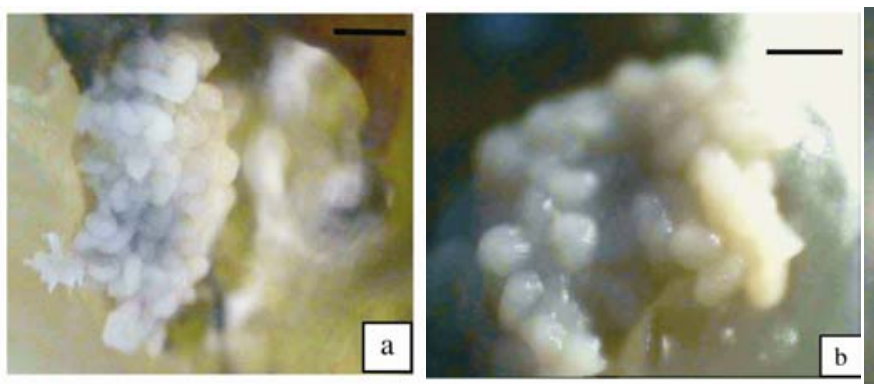

Fig. 4. Phytochemical analysis of the embryogenic mass.

(a) HPLC analysis of the ethanolic extracts of the embryogenic mass; (b) mass spectrogram of a TIC peak of the dichloromethane extract similar to betasitosterol .

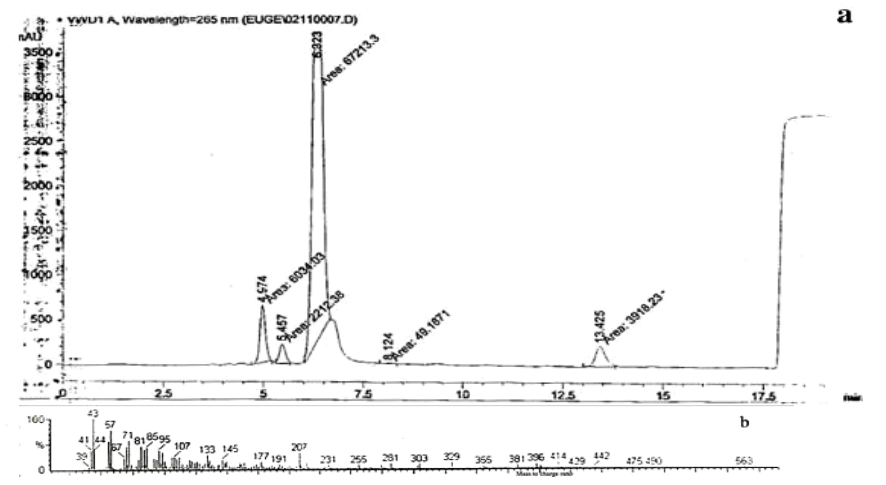

Research article (Rapid publication) CIndian Society for Education and Environment (iSee)
Vol.2 No 4 (Mar. 2009)

ISSN: $0974-6846$
Fig. 1. Somatic embryogenesis in zygotic embryo explants of $M$. fragrans

(a) Somatic embryo; (b) Embryogenic mass. $($ bar $=1 \mathrm{~mm})$.

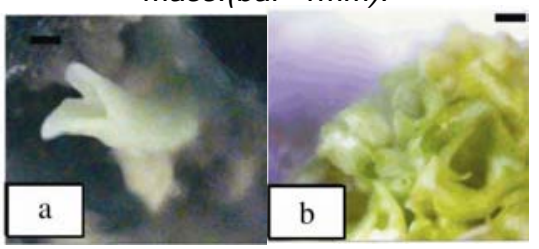

Fig. 2. Germination of somatic embryos. (a) Root formation in somatic embryos in media

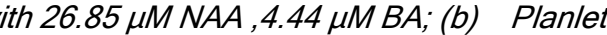
$T D Z$ and $14.43 \mu M \mathrm{GA}_{3}$ ( bar $\left.=1 \mathrm{~mm}\right)$.

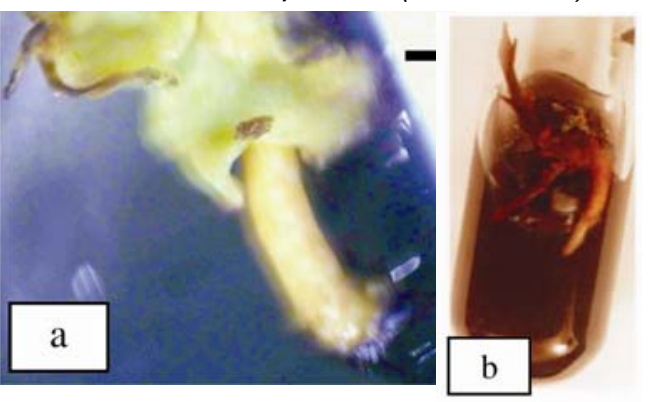

Direct somatic embryogenesis in leaf pieces

Unlike zygotic embryos no massive leaching of phenolics into the medium could be observed from foliar explants presumably owing to the lower levels of phenolics in the leaf explants. Hence leaf tissues could be successfully cultured in the

absence of activated charcoal. Induction of direct somatic embryogenesis was obtained after four weeks of culture in MS media with 2,4-D (22.62 $\mu \mathrm{M})$, kinetin $(13.95 \mu \mathrm{M})$ and NAA $(16.11 \mu \mathrm{M})$ in tender leaf pieces. The response was observed in the laminar region near the midvein. However the percent response was only $6.66 \%$. The somatic embryos were initially whitish and opaque but later became transluscent and pale yellow (Fig.3a, b). Following induction, the somatic embryos developed synchronously in about two to three months and after transfer to medium of the same composition underwent rapid elongation (Fig.3c). Hence explants from immature leaves of juvenile plants are potentially more suitable for induction of normal somatic embryos than zygotic embryo explants since no abnormalities could be detected in the leaf-derived somatic embryos.

Phytochemical profiling of the embryogenic mass from zygotic embryos

Headspace GCMS analysis revealed a rich molecular diversity in the embryogenic cultures reflecting the profile in vivo. Table 3 reveals that the secondary metabolite profile in the embryogenic cultures varied with the age of

Fig. 5 (a, b). Anti- bacterial activity against Staphylococcus aureus and Salmonella typhi respectively.
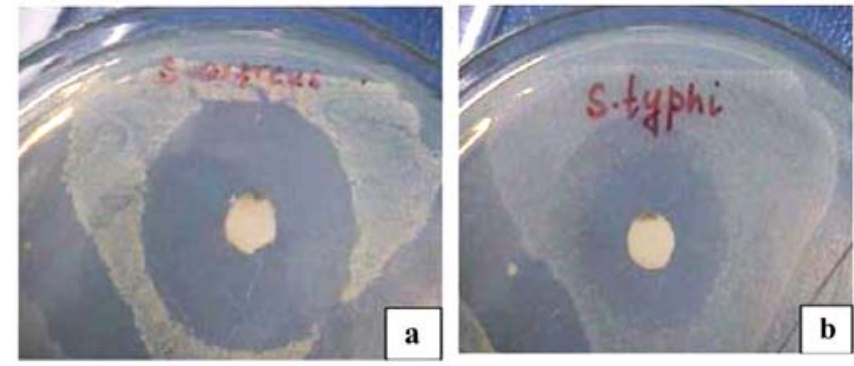

Indira lyer et al. Indian J.Sci.Technol. 
Table 1 .Embryogenic responses of zygotic embryos of Myristica fragrans initially cultured in MS media with activated charcoal and various combinations of plant growth regulators $(\mu M)$.

\begin{tabular}{|c|c|c|c|c|c|c|}
\hline NAA & BA & TDZ & Kinetin & $2,4-\mathrm{D}$ & IAA & \% somatic embryogenesis \\
\hline 26.85 & 4.44 & - & - & - & - & $100(90) \mathrm{d}$ \\
\hline 26.85 & 4.44 & - & - & - & - & $79.15(69.88) \mathrm{bc}^{*}$ \\
\hline 21.48 & 4.44 & - & - & - & - & $66.65(62.62) \mathrm{b}$ \\
\hline 13.42 & 22.2 & - & - & - & - & $92.8(74.43) \mathrm{bc}$ \\
\hline 5.37 & 8.87 & - & - & - & - & $80(70.38) \mathrm{bc}$ \\
\hline 5.37 & 22.2 & - & - & - & - & $100(90) \mathrm{d}$ \\
\hline 26.85 & 13.3 & 0.72 & - & - & - & $93.75(79.64) \mathrm{cd}$ \\
\hline 21.48 & 8.87 & - & 9.29 & - & - & $46(42.34) \mathrm{a}$ \\
\hline 10.74 & 4.4 & - & - & 22.6 & - & $83.3(72.34) \mathrm{bc}$ \\
\hline 21.48 & 8.87 & - & - & - & 22.8 & $100(90) \mathrm{d}$ \\
\hline- & 8.87 & - & - & - & - & $87.5(75) \mathrm{bc}$ \\
\hline
\end{tabular}

*Medium 2 had MS salts at half the level; a. Values in parentheses are arcsine

transformation values of percentage of response. Means followed by the same letters are not significantly different at $P<0.05$ level according to Fisher's $L S D$ test .
Vol.2 No 4 (Mar. 2009)

ISSN: 0974- 6846 was tentatively identified as $\beta$-sitosterol on the basis of its mass spectral fragmentation pattern (Fig. 4 b). A compound that appeared to be similar to the aromatic ether methoxy eugenol was detected by GCMS analysis of the ethanolic extract of the embryogenic mass.

Many of the volatile components detected in the embryogenic cultures of nutmeg including a-pinene, sabinene and methoxy eugenol are reported to be associated with antimicrobial and antioxidant activities (Singh et al., 2005). Anti-cancer properties have been attributed to safrole derivatives, myristicin, $\beta$ sitosterol and methyl eugenol (Ju et al., 2004; Lee et al., 2005; Du et al., 2006; Pisano et al., 2007). There are also reports of the hepatoprotective and hypotensive effects of myristicin and methyl eugenol (Morita et al., 2003; Lahlou et al., 2004) respectively. the embryogenic cultures. A greater diversity of monoterpenes was detected in 3 week old cultures in which several known essential oils and terpenes were detected. In 5 week old embryogenic cultures, the terpenes $\alpha$ - pinene, sabinene and $\beta$ - pinene were detected, though at a lower concentration than in 3 week old cultures, along with the phenylpropanoid ether myristicin. Compounds with retention time similar to p-methoxyamphetamine could be detected in 5 week old cultures and these could be derivatives of myristicin and other components of nutmeg (Pytte \& Rygnestad, 1998). No volatiles could be detected in one week old cultures. HPLC analysis of the ethanolic extract (Fig.4a) revealed the presence of methyl eugenol $(84.62 \%)$, myristicin $(4.33 \%)$ and safrole $(0.06 \%)$. The high level of methyl eugenol (Table 4) in the embryogenic mass is consistent with its reported role as precursor of phenylpropenes in a number of aromatic species (Sangwan et al., 2001).

GCMS analysis of the dichloromethane extract revealed the presence of several peaks one of which

Table 2. Germination of somatic embryos after subculture in MS media containing activated charcoal $(0.3 \%), N A A$ with other growth regulators $(\mu M)$

\begin{tabular}{|c|c|c|c|}
\hline NAA & BA & TDZ & \% germination of somatic embryos ${ }^{\mathrm{a}, \mathrm{b}}$ \\
\hline 26.85 & 4.44 & - & $25.63(29.94) \mathrm{c}$ \\
\hline 26.85 & 4.44 & - & $15.83(23.35) \mathrm{b}^{*}$ \\
\hline 26.85 & 4.44 & 0.45 & $6.11(13.95) \mathrm{a}$ \\
\hline
\end{tabular}

*Medium 2 had MS salts at half the level; a. Values in

parentheses are arcsine transformation values of percentage of response. Means followed by different letters are significantly different at the $P<0.05$ level according to Fisher's $L S D$ test. b. Germination indicates root development
Table 3. Some of the phenylpropanoids detected in 3 and 5 week old embryogenic cultures of nutmeg by headspace GC-MS*

\begin{tabular}{|c|c|c|c|}
\hline \multicolumn{2}{|c|}{3 week old cultures } & \multicolumn{2}{c|}{5 week old cultures } \\
\hline $\begin{array}{c}\text { Compounds } \\
\text { detected }\end{array}$ & $\begin{array}{c}\text { Abundance } \\
(\%)\end{array}$ & $\begin{array}{c}\text { Compounds } \\
\text { detected }\end{array}$ & $\begin{array}{c}\text { Abundance } \\
\text { (\%) }\end{array}$ \\
\hline a-pinene & 23 & a-pinene & 16.615 \\
\hline sabinene & 5 & sabinene & 4.46 \\
\hline$\beta$-pinene & 15 & $\beta$-pinene & 10.84 \\
\hline$\beta$ - myrcene & 2 & $\begin{array}{c}\text { p-methoxyam } \\
\text {-phetamine }\end{array}$ & 0.8 \\
\hline limonene & 1 & myristicin & 8.95 \\
\hline cis $\beta$-ocimene & 7 & - & - \\
\hline$\gamma$ - terpinene & 3 & - & - \\
\hline terpinolene & 3.6 & - & - \\
\hline terpinen-4-ol & 15 & - & - \\
\hline myrcenol & 8.4 & - & - \\
\hline
\end{tabular}

*The ion current generated depends on the characteristics of the compound and is not a true quantitation.

Amphetamine derivates are used in treatment of attention deficit hyperactivity disorder (Solanto, 1998). Metabolite profiling of embryogenic cultures from zygotic embryos after elicitor treatment

Headspace GC-MS analysis after treatment with chitosan revealed the presence of methyl salicylate along with monoterpenes (Table 5) and other volatiles.

Anti- bacterial activity of the spent charcoal medium of the embryogenic cultures from zygotic embryos: Disc diffusion assay
Research article (Rapid publication)

CIndian Society for Education and Environment (iSee)
"Embryogenic culture of nutmeg" http://www.indjst.org
Indira lyer et al. Indian J.Sci.Technol. 
Disc diffusion assay (Fig. $5 a \&$ b) revealed that the ethanolic extract $(5 \mu \mathrm{L})$ of the spent medium with the inhibitory substances leached out of the zygotic embryo explants and adsorbed by activated charcoal could strongly inhibit the growth of the bacteria Salmonella typhi and Staphylococcus aureus. This is consistent with our earlier observations that activated charcoal was crucial for the survival and proliferation of the cultured zygotic embryo explants (lyer et al., 2000) because of its effective adsorption and sequestration of the metabolites leached out into the medium thus preventing their inhibitory effect on the explants. The results indicate the possibility for utilization of the inhibitory metabolites in the spent medium for the development of effective therapeutic agents and is significant especially in the context of the existence of strains of Staphylococcus aureus known to be resistant to all conventional antibiotics and multidrug resistant strains of Salmonella typhi (Hughes, 2003; Rani \& Khullar, 2004).

Detection of the active principle in the spent charcoal medium

GC-MS analysis of the ethanolic extract of the spent charcoal medium revealed the presence of several compounds. A prominent peak (68.49\%) which was similar to the purine alkaloid xanthosine, a nucleic acid base analogue was present. The presence of compounds similar to nucleic acid base analogues in the spent medium indicates its potential in development of new leads for drugs since such molecules can block nucleic acid synthesis and this can result in antiproliferative, anti-parasitic and anti-HIVIAIDS effects (Franchetti \& Grifantini, 1999).

The present work assumes significance in the context that to the best of our knowledge it is the first time report of establishing embryogenic culture system in nutmeg for the in vitro production of $\alpha \& \beta$-pinene, sabinene, myristicin, safrole and methyl eugenol and other essential oils as well as betasitosterol and also the elicitation of production of methyl salicylate by chitosan in the embryogenic cultures.

Furthermore, the spent charcoal medium of the embryogenic cultures has also been shown to have strong anti-microbial activity against Salmonella typhi and Staphylococcus aureus indicating their potential for application in new approaches for the development of lead molecules with medicinal activity. The in vitro produced biomass and the spent charcoal medium may be developed as renewable and readily available source of plant material and

Research article (Rapid publication)

CIndian Society for Education and Environment (iSee)

phytochemicals for large- scale extraction of the valuable compounds after further refinements in technology to improve the yield. Since the seeds of this rare, slowgrowing tree are recalcitrant, the embryogenic mass is also ideally suitable for utilization in strategies for ex-situ conservation by cryopreservation (Panis \& Lambardi, 2006) and can facilitate exchange of germplasm. The work is equally significant as the regeneration of in vitro plantlets in embryogenic cultures initiated from zygotic embryos has been achieved since failure of germination of somatic embryos is a major limiting factor in the micropropagation of woody species (Jain, 2006). Further work is needed to reduce the developmental abnormalities in somatic embryogenesis in nutmeg for improvement of germination and successful establishment of plantlets under ex-vitro conditions. The development of normal somatic embryos in leaf explants from juvenile material points to their potential in future studies as promising non-embryonic explant sources for regeneration into plantlets.

Acknowledgement

The work was funded by a project awarded to R. Indira lyer under the DST Women Scientists Scheme (SR/WOS-A/LS-400/2003) by the Department of Science \& Technology, Govt. of India.

References

1. Blázquez S, Piqueras $A$, Serna, MD, Casas JL and Fernández JA (2004) Somatic embryogenesis in saffron: optimisation through temporary immersion and polyamine metabolism. Acta Horticulturae, 650, 269276.

2. Canhoto JM, Rama SC and Cruz GS (2006) Somatic embryogenesis and plant regeneration in carob (Ceratonia siliqua L.). In Vitro Cell Dev. Biol - Plant. 42, 514-519.

Table 4. Compounds detected by HPLC analysis of the ethanolic extract of embryogenic cutures of nutmeg

\begin{tabular}{|c|c|}
\hline Compound detected & Abundance (\%) \\
\hline methyl eugenol & 84.62 \\
\hline safrole & 0.06 \\
\hline myristicin & 4.33 \\
\hline
\end{tabular}

Table 5. Some of the compounds detected by headspace GC-MS of embryogenicmass after chitosan treatment $\left(100 \mathrm{mg} \mathrm{L}^{-1}\right)$ *

\begin{tabular}{|c|c|c|}
\hline $\begin{array}{c}\text { Retention } \\
\text { time (min ) }\end{array}$ & $\begin{array}{c}\text { Compounds } \\
\text { identified }\end{array}$ & $\begin{array}{c}\text { Abundance } \\
(\%)\end{array}$ \\
\hline 5.41 & a-pinene & 3.15 \\
\hline 6.03 & sabinene & 3.52 \\
\hline 6.15 & $\beta$-pinene & 3.53 \\
\hline 9.62 & $\begin{array}{c}\text { methyl } \\
\text { salicylate }\end{array}$ & 6.89 \\
\hline
\end{tabular}

*The ion current generated depends on the characteristics of the compound and is not a true quantitation.

"Embryogenic culture of nutmeg" http://www.indjst.org
3. Chaturvedi HC, Agnihotri S, Sharma M, Sharma AK, Jain M and Chourasia A (2003) In vitro control of fasciation in proliferating nucellar embryos of Mangifera indica L. var totapari red small for cloning. Indian J. Exp. Biol. 41, 1311-1316.

4. Chirathaworn C, Kongcharoensuntorn W, Dechdoungchan

Lowanitchapat A, Sa-Nguanmoo $P$ and Yong $P$ (2007) Myristica fragrans Houtt. methanolic extract induces apoptosis in a human leukemia cell line through SIRT1 mRNA downregulation. J. Med. Assoc. Thai. 90, 2422-2428.

5. Distabanjong $\mathrm{K}$ and Geneve RL (1977) Multiple shoot formation from normal and malformed somatic embryo explants of Eastern redbud (Cercis Indian J.Sci.Technol. 
canadensis L.). Plant Cell Rep. 16, 334-338.

6. Du A, Zhao B, Miao, J, Yin D, and Zhang S (2006) Safrole oxide induces apoptosis by up-regulating Fas and FasL instead of integrin $\beta 4$ in A549 human lung cancer cells. Bioorg. Med. Chem. 14, 2438-2445.

7. Ehlers D, Kirchhoff J, Gerard D and Quirin KW (1998) High-performance liquid chromatography analysis of nutmeg and mace oils produced by supercritical $\mathrm{CO}_{2}$ extraction- Comparison with steam distilled oilscomparison of East Indian, West Indian and Papuan oils. Int.J. Food Sci. Tech. 33, 215-223.

8. Franchetti $P$ and Grifantini M (1999) Nucleoside and non-nucleoside inhibitors as antitumor and antiviral agents. Curr. Med. Chem. 6, 599-614.

9. Gómez-Lim MA and Litz RE (2004) Genetic transformation of perennial tropical fruits. In Vitro Cell Dev. Biol. - Plant. 40, 442-449.

10. Hughes D (2003) Microbial genetics. Exploiting genomics, genetics and chemistry to combat antibiotic resistance. Nat. Rev. Genet. 4, 432-441.

11. Iyer RI (2007) In vitro propagation of nutmeg, Myristica fragrans Houtt. In: Protocols For Micropropagation Of Woody Trees And Fruits (eds. Haggman H \& Jain SM ), pp: 335-344, Springer, The Netherlands.

12. Iyer RI, Jayaraman G, Gopinath PM and Lakshmi Sita G (2000) Direct somatic embryogenesis in zygotic embryos of nutmeg (Myristica fragrans Houtt.) Trop. Agric.(Trinidad). 77, 98-105.

13. Jain SM (2006) An updated overview of advances in somatic embryogenesis in forest trees. In: Plantation Technology in Tropical Forest Science, Part II B (eds. Suzuki K, Ishii K, Sakurai S and Sasaki S), pp:113-122. Springer, Tokyo.

14. Jorgensen JH, Turnidge JD and Washington JA (1999) Antibacterial susceptibility tests: dilution and disk diffusion methods. In: Manual of Clinical Microbiology, 7th ed. (eds. Murray PR, Pfaller MA, Tenover FC, Baron EJ \& Yolken RH), pp: 1526-1543. ASM Press, Washington, DC

15. Ju $\mathrm{YH}$, Clausen LM, Allred KF, Almada $A L$ and Helferich WG (2004) Beta-sitosterol, beta-sitosterol glucoside, and a mixture of beta-sitosterol and betasitosterol glucoside modulate the growth of estrogenresponsive breast cancer cells in vitro and in ovariectomized athymic mice. J. Nutr. 134, 1145-1151.

16. Komaraiah $P$, Ramakrishna SV, Reddanna $P$ and Kavi Kishor PB (2003) Enhanced production of plumbagin in immobilized cells of Plumbago rosea by elicitation and in situ adsorption. J. Biotechnol. 101, 181-187.

17. Koulman A, Bos R, Medarde M, Pras N and Quax WJ (2001) A fast and simple GC MS method for lignan profiling in Anthriscus sylvestris and biosynthetically related plant species. Planta Medica. 67, 858-862.

18. Lahlou S, Figueiredo AF, Magalhães PJC, LealCardoso JH and Gloria PD (2004) Cardiovascular effects of methyleugenol, a natural constituent of many plant essential oils in normotensive rats. Life Sci. 74, 2401-2412.

19. Latha PG, Sindhu PG, Suja SR, Geetha BS, Pushpangadan $P$ and Rajasekharan S (2005)
Pharmacology and chemistry of Myristica fragrans Houtt. -a review. J. Spices \& Aromatic Crops. 14, 94101.

20. Lee BK, Kim JH, Jung JW, Choi JW, Han ES, Lee SH, $\mathrm{Ko}, \mathrm{KH}$ and Ryu JH (2005) Myristicin-induced neurotoxicity in human neuroblastoma SK-N-SH cells. Toxicol. Lett. 157, 49-56.

21. Merkle SA and Nairn CJ (2005) Hardwood tree biotechnology. In Vitro Cell Dev. Biol.- Plant. 41, 602619.

22. Morita $\mathrm{T}$, Jinno $\mathrm{K}$, Kawagishi $\mathrm{H}$, Arimoto $\mathrm{Y}$, Suganuma, $H$, Inakuma $T$ and Sugiyama $K$ (2003) Hepatoprotective effect of myristicin from nutmeg (Myristica fragrans) on lipopolysaccharide/dgalactosamine-induced liver injury. J. Agric. Food Chem. 51, 1560-1565.

23. Murashige $T$ and Skoog $F$ (1962) A revised medium for rapid growth and bioassays with tobacco tissue cultures. Physiol. Plant. 15, 473-497.

24. Panis B and Lambardi M (2006) Status of cryopreservation technologies in plants (crops and forest trees). In: The Role Of Biotechnology In Exploring And Protecting Agricultural Genetic Resources (eds. Ruane $\mathrm{J}$ and Sonnino A), pp: 61-78. FAO, Rome.

25. Pisano $M$, Pagnan $G$, Loi $M$, Mura, ME, Tilocca MG, Palmieri G, Fabbri D, Dettori, MA, Delogu G, Ponzoni $M$ and Rozzo C (2007) Antiproliferative and proapoptotic activity of eugenol-related biphenyls on malignant melanoma cells. Molecular Cancer [online], 18 January 2007, vol. 6, article no.8 doi:10.1186/14764598-6-8 (extracted on 18 January 2007). Domain: http://www.molecular-cancer.com/content/6/1/8.

26. Pytte $M$ and Rygnestad T (1998) Nutmeg- more than a spice. Tidsskr Nor Laegeforen. 118, 4346-4347.

27. Rani $P$ and Khullar N (2004) Antimicrobial evaluation of some medicinal plants for their anti-enteric potential against multi-drug resistant Salmonella typhi. Phytother. Res. 18, 670-673.

28. Sangwan NS, Farooqi AHA, Shabih $F$ and Sangwan RS (2001) Regulation of essential oil production in plants. Plant Growth Regulation. 34, 3-21.

29. Singh G, Marimuthu P, De Heluani CS and Catalan C (2005) Antimicrobial and antioxidant potentials of essential oil and acetone extract of Myristica fragrans outt (aril part). J. Food Sci. M141 - M148.

30. Solanto MV (1998) Neuropsychopharmacological mechanisms of stimulant drug action in attention-deficit hyperactivity disorder: a review and integration. Behavioural Brain Res., 94, 127-152.

31. Trigiano RN, Buckley LG and Merkle SA (1999) Somatic embryogenesis in woody legumes. In: Somatic embryogenesis in woody plants: vol. 4 (Forestry sciences) (eds. Jain SM, Gupta PK and Newton RJ), pp: 198-208. Kluwer Academic Publishers, Dordrecht, The Netherlands.

32. Yang S, Kyun NM, Jang JP, Kyung AK, Kim BY, Sung NJ, Oh WK and Ahn JS (2006) Inhibition of protein tyrosine phosphatase $1 \mathrm{~B}$ by lignans from Myristica fragrans. Phytother. Res. 20, 680-682. 